\title{
Tumor de cordón sexual con túbulos anulares y cistadenoma mucinoso de ovario en una adolescente con síndrome de Peutz-Jeghers
}

\author{
Sex cord tumor with annular tubules and mucinous \\ cystadenoma of the ovary in a teenage girl with Peutz- \\ Jeghers syndrome
}

Rosalía Garza-Elizondo, ${ }^{1}$ María Teresa Silva-Martínez, ${ }^{2}$ Ariadna González-del Ángel, ${ }^{3}$ Denisse Fuentes-Gutiérrez, ${ }^{4}$ Eduardo López-Corella ${ }^{4}$

\section{HISTORIA CLÍNICA}

Niña de 14 años, con antecedente de prolapso de pólipo rectal con evacuaciones sanguinolentas a los 12 meses de edad, atendida en el Instituto Nacional de Pediatría. Procedente del segundo embarazo de una pareja con padre sano y madre afectada con el síndrome de PeutzJeghers, al igual que otros familiares por la rama materna. Antecedente de aborto en la madre y hermana menor aparentemente sana. La madre tuvo amenaza de parto pretérmino en el séptimo mes, que se controló con reposo y medicamentos no especificados. La paciente nació por cesárea a las 41 semanas de edad gestacional, por falta de trabajo de parto. Tuvo Ilanto y respiración espontáneos, Apagar de 8-9, peso de $3.8 \mathrm{~kg}$ y talla de $51 \mathrm{~cm}$. Fue dada de alta como binomio sano a las 78 horas del evento obstétrico. El periodo posnatal cursó sin complicaciones y su desarrollo neurológico transcurrió normal.

Acudió al servicio de Urgencias al año de edad, con prolapso del pólipo, que fue reducido pero continuó 3-4 veces por semana. En estas condiciones se ingresó al instituto. Los signos vitales y somatometría se reportaron peso $10.3 \mathrm{~kg}$, talla $78 \mathrm{~cm}, \mathrm{PC} 47 \mathrm{~cm}, \mathrm{FC} 110$ por minuto, FC 30 por minuto y temperatura $36.8^{\circ} \mathrm{C}$.

Fue atendida en el servicio de Genética a los 18 meses de edad, donde se elaboró el árbol genealógico (Figura 1) y se describieron: manchas hipercrómicas en labio inferior, e hiperpigmentadas en las palmas y los labios de la madre.

\footnotetext{
${ }^{1}$ Departamento de Consulta externa. ${ }^{2}$ Departamento de Radiología e imagen.

${ }^{3}$ Laboratorio de Biología molecular

${ }^{4}$ Departamento de Patología.

Instituto Nacional de Pediatría, Ciudad de México.

Recibido: 18 de junio 2020

Aceptado: 30 de junio 2020

Correspondencia

Eduardo López Corella

tarto006@gmail.com

Este artículo debe citarse como Garza-Elizondo R, Silva-Martínez MT, González-del Ángel A, Fuentes-Gu tiérrez $D$, López-Corella $E$. Tumor de cordón sexual con túbulos anulares y cistadenoma mucinoso de ovario en una adolescente con síndrome de Peutz-Jeghers. Acta Pediatr Mex 2020; 41(4): 178-186.

DOI: http://dx.doi.org/10.18233/APM41No4pp178-1862098
} 


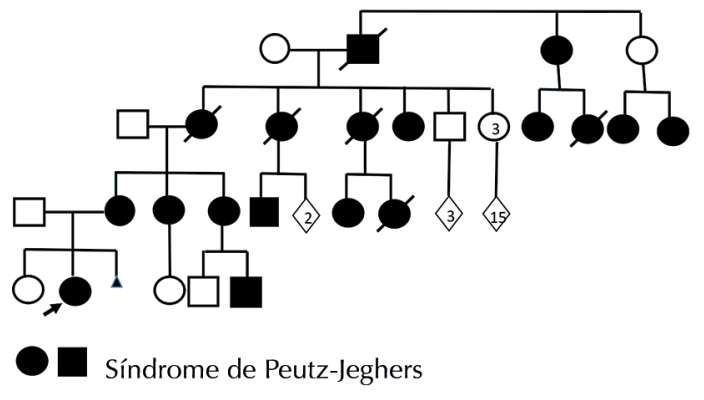

Figura 1. Árbol genealógico de la paciente.

La paciente continuó en seguimiento por área de Consulta externa, a cargo del servicio de Gastronutrición, con colonoscopias cada dos años; desde los 3 hasta los 14 años se le habían realizado 10 resecciones con extirpación de numerosos pólipos hamartomatosos en el estómago, duodeno, colon y rectosigmoides. A los 5 años de edad, un pólipo en transverso provocó oclusión intestinal, con invaginación colo-colónica desde el transverso hasta el recto, que se resolvió por cirugía (B08-2171), con un segundo procedimiento para resolver un cuadro oclusivo por adherencias (B08-2241).

A los 12 años y 10 meses fue atendida por primera vez por el servicio de Ginecología. Tuvo telarquia y pubarquia a los 11 años, y menarquia a los 12 años de edad. Se observó una masa en la axila izquierda, no dolorosa, constituida por tejido organizado, de $4 \mathrm{~cm}$ de diámetro, con pezón accesorio, Tanner mamario V. El ultrasonido mostró imágenes con ecos mixtos en ambas axilas; hipo e hiperdensos en la periferia, e hiperdensos en el centro en ambas axilas, de 2 $\mathrm{cm}$ de diámetro, correspondientes a ganglios. El ultrasonido mamario evidenció: masa con patrón fibroglandular tipo B sin lesiones.
Entre los 12 y 13 años y medio, cuatro ultrasonidos pélvicos revelaron un quiste con crecimiento progresivo en el ovario izquierdo (ver comentario radiológico adelante).

Refería ciclos menstruales irregulares, con duración de 5-8 días, inicialmente sin dismenorrea. No señaló haber iniciado su vida sexual. El perfil hormonal mostró: TSH $3.25 \mu \mathrm{UI} / \mathrm{mL}$ [0.4-4], T4L 0.9 ng/dL [0.8-1.9], LH $1.9 \mathrm{mUl} / \mathrm{mL}, \mathrm{FSH}$ $4.7 \mathrm{mUl} / \mathrm{mL}$, estradiol $42.6 \mathrm{pg} / \mathrm{mL}(0.1-56)$ y prolactina $6.0 \mathrm{ng} / \mathrm{mL}$ [2.5-17.8]. Se indicó metilprogesterona cíclica en fase lútea, pero fue administrada de forma irregular. Se agregó etinil estradiol y drospirenona.

Los marcadores tumorales reportaron: AFP 0.6 $\mathrm{UI} / \mathrm{mL}$ [0.5-5.5], BHGC $<2 \mathrm{ng} / \mathrm{mL}$ [0-00-2.00], Ca-125 (extra INP) $16.40 \mathrm{U} / \mathrm{mL}[<35]$. Cursó con anemia hipocrómica mircrocítica por los abundantes sangrados y fue tratada con sulfato ferroso.

Entre los 13-14 años tuvo dismenorrea leve y se mantuvo en seguimiento ginecológico. No hubo respuesta a tres ciclos de estrógeno-progestina y los marcadores tumorales se reporaron negativos.

A los 14 años y 1 mes la paciente se sometió a cirugía. El peso era de $63.850 \mathrm{~kg}$, (p 75) y la talla 1.69 ( $\mathrm{p}$ 75-90).

\section{Estudios de imagen}

Dra. Silva Martínez

A continuación se muestran los tres estudios más relevantes. El ultrasonido pélvico a los 12 años y medio reportó: útero de 55 x 35 x 41 mm, endometrio de $6 \mathrm{~mm}$, ovario derecho de $3.7 \mathrm{cc}$, con folículos de 16 mm de diámetro; el ovario izquierdo medía 20.5 cc, tenía una lesión anecóica de 11.3 cc, con reforzamiento acústico posterior, de bordes regulares y definidos. Figura 2 
Seis meses después, el ultrasonido (Figura 3) mostró: ovario izquierdo de gran volumen (75 $\mathrm{mL}$ ) a expensas de una imagen ovalada, de pared delgada, anecóica, de 35.4 cc, sin alteración a la aplicación de Doppler color. Finalmente, a los 13 años y medio, el ovario izquierdo (Figura 4) persistió de gran volumen $(90.9 \mathrm{~mL})$, por lesión anecóica y homogénea, sin mostrar alteración con la aplicación de Doppler color.

\section{Comentario anatomopatológico}

Dra. Fuentes y Dr. López Corella

Durante los casi 15 años de atención a la paciente se le han resecado numerosos pólipos, más de 30, del tracto digestivo, en el estómago, intestino delgado y colon, todos con antecedente de pólipo hamartomatoso, que representa una característica fundamental del síndrome de Peutz-Jeghers. (Figura 5) La historia familiar y la pigmentación mucocutánea coinciden con el diagnóstico de síndrome de Peutz Jeghers en nuestra paciente.

Los pacientes con Peutz-Jeghers tienen una bien documentada predisposición a desarrollar una diversidad de neoplasias, benignas y malignas, no solo en el tracto intestinal donde suelen estar los pólipos, también en páncreas, en el tracto genital sobre todo en mujeres y en muchas otras localizaciones. ${ }^{1}$ Aunque en pacientes de edad pediátrica es poco frecuente la neoplasia, el
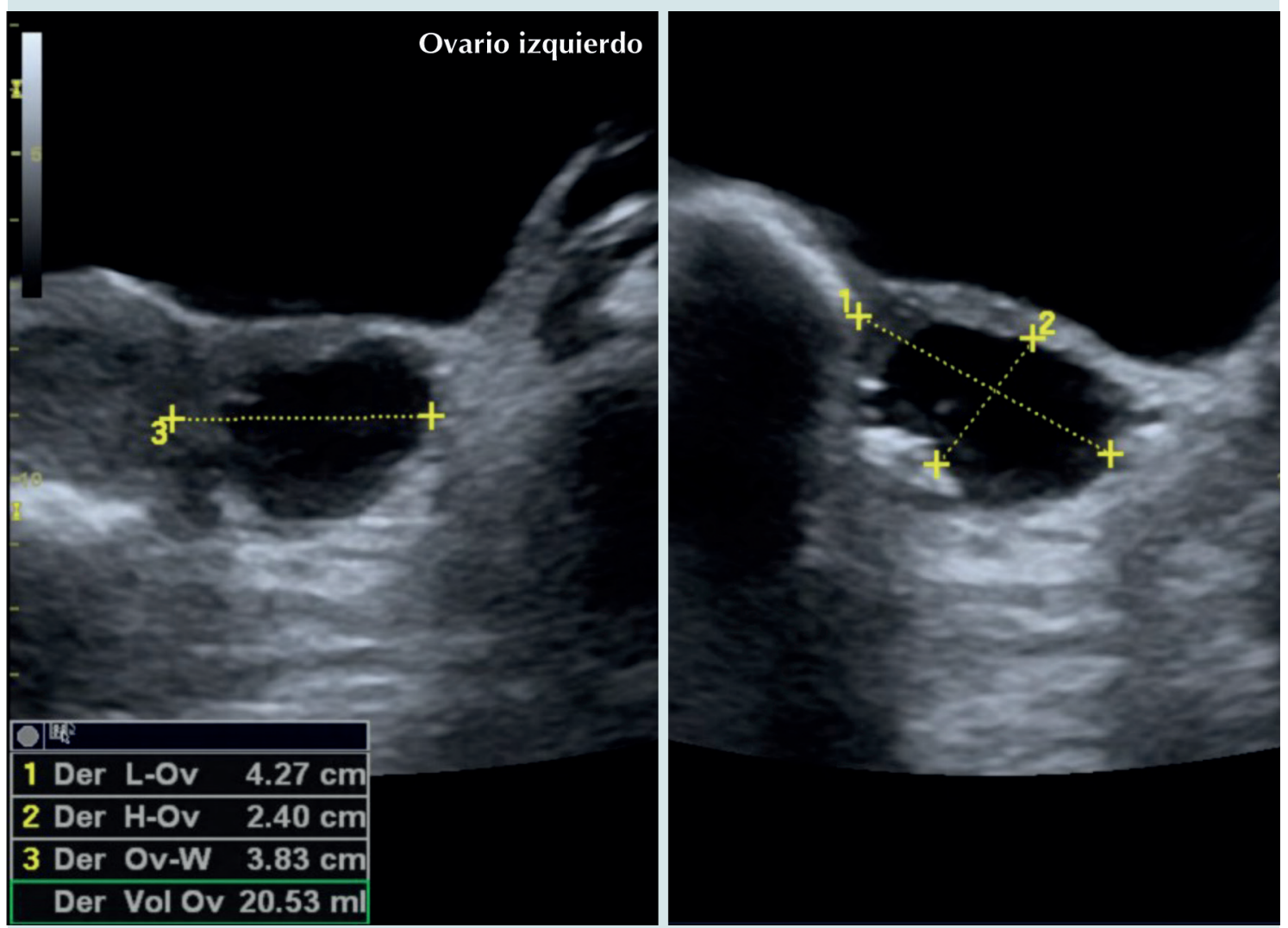

Figura 2. Ultrasonido pélvico a los 12.5 años de edad. Quiste simple de ovario izquierdo. 
Garza-Elizondo R, et al. Tumor ovárico de cordón sexual y síndrome de Peutz-Jeghers

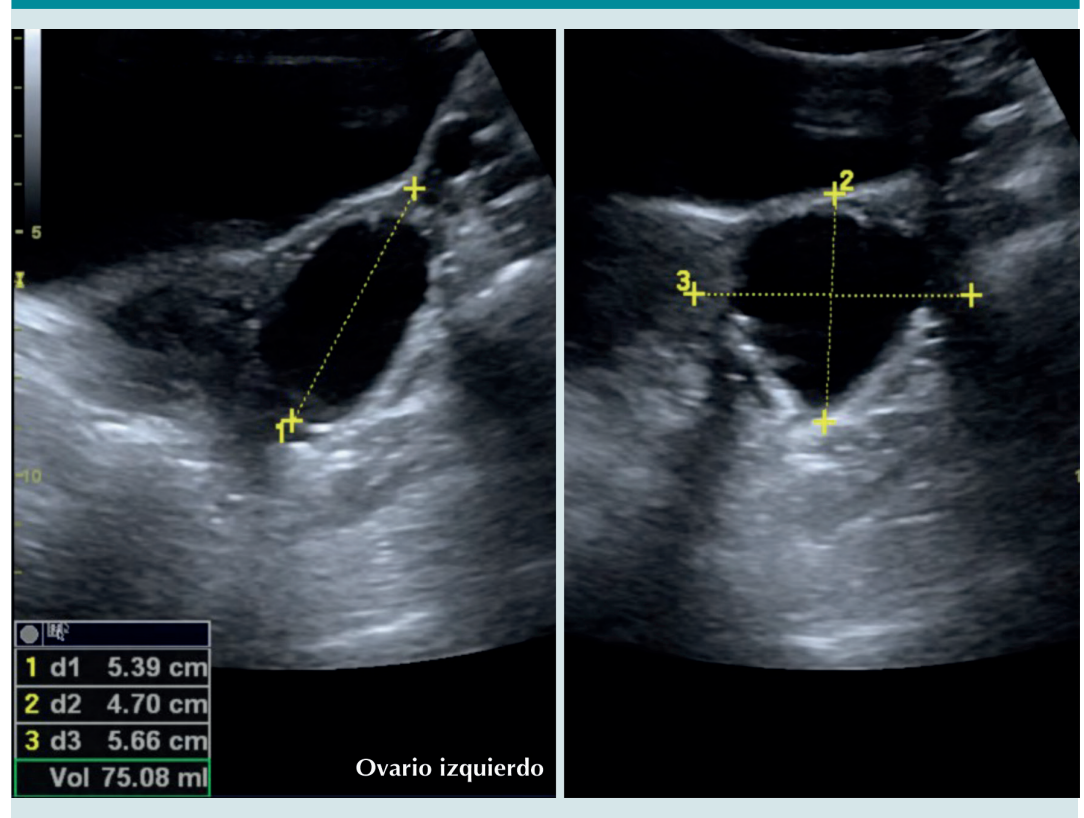

Figura 3. Ultrasonido pélvico seis meses después del anterior. Incremento del quiste en el ovario izquierdo, incluso 50\% con respecto al estudio previo.
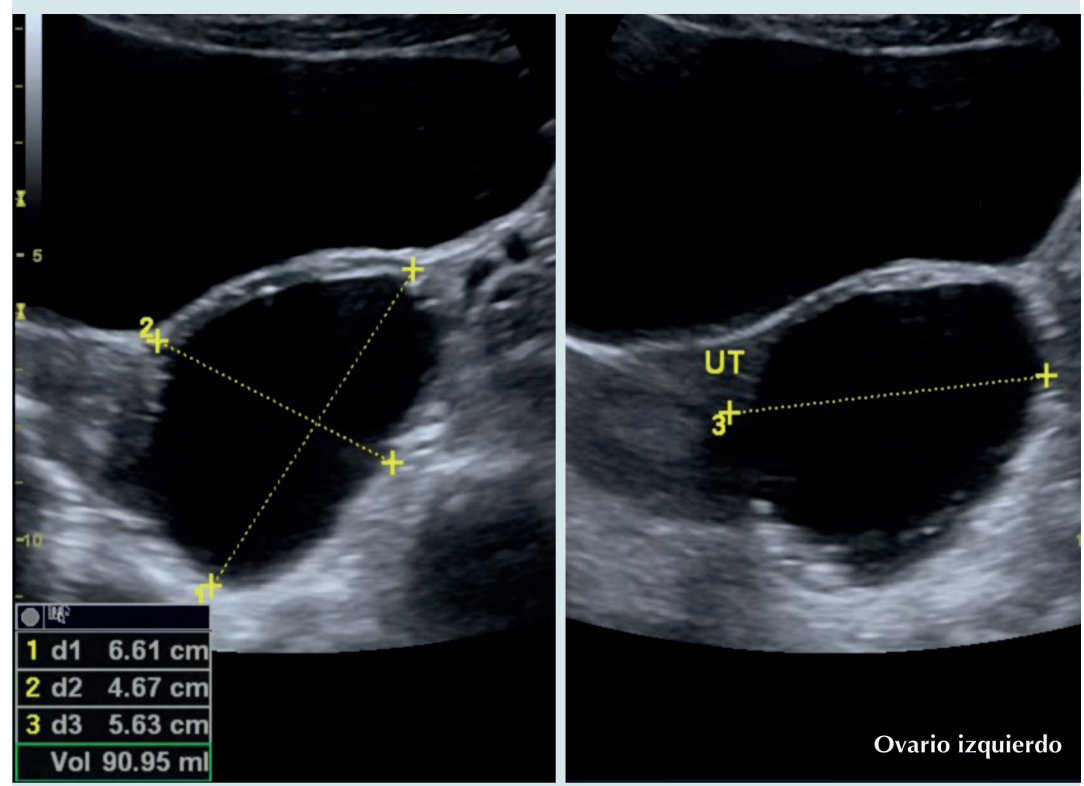

Figura 4. Ultrasonido pélvico a los 13.5 años de edad. Ovario izquierdo (corte longitudinal y transversal) de $90.9 \mathrm{~mL}$. 

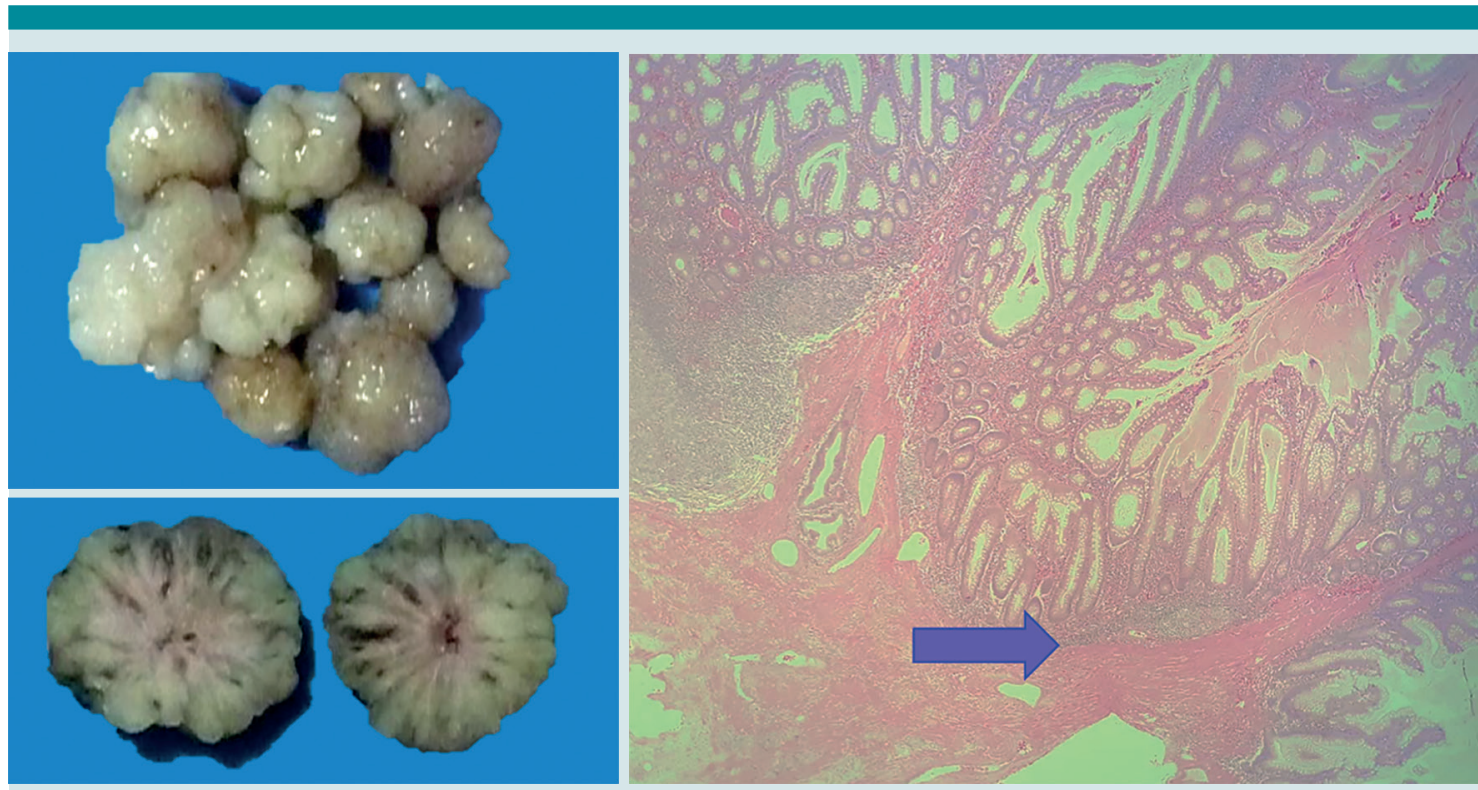

Figura 5. Pólipos hamartomatosos de la paciente. En la imagen microscópica se observan haces de músculo liso (flecha), entre las glándulas intestinales tortuosas.

riesgo aumenta conforme avanza la edad, por lo que los pacientes afectados con este síndrome, que suelen ser niños o adolescentes, deben tener seguimiento activo y dirigido por un alto grado de sospecha durante toda la vida.

Nuestra paciente, ya con el diagnóstico sindromático bien establecido, al entrar a la adolescencia manifestó una masa en el ovario izquierdo, que simulaba un quiste en los estudios de imagen, pero al mostrar un crecimiento acelerado fue resecado.

Recibimos el anexo izquierdo, con el ovario remplazado por un tumor multiloculado con varias formaciones quísticas, la mayor de 6.5 $\mathrm{cm}$ de diámetro (Figura 6), todas estas revestidas por epitelio mucinoso, de núcleos basales uniformes, sin estratificación ni atipia, con morfología diagnóstica de cistadenoma mucinoso. Había prominentes placas calcificadas en el estroma, hallazgo poco común en este tumor (Figura
7). En el tejido ovárico conservado destacaban grupos dispersos de estructuras epiteliales con morfología de túbulos anulares, característica de un tumor benigno de cordón sexual con túbulos anulares, o tumor de Scully (Figura 8). Este último con identificación y primera descripción en 1970, efectuada por Robert E. Scully del Massachusetts General Hospital. Desde la primera publicación se hacía notar la asociación con el síndrome de Peutz-Jeghers. ${ }^{2}$ La experiencia acumulada desde entonces reafirma esta asociación; 1 de cada 3 de estos tumores se asocia con el síndrome. Destaca, además, la diferencia entre los casos de tumor de cordón sexual con túbulos anulares asociados con el síndrome de PeutzJeghers, que tienden a ser multifocales, pequeños y a menudo microscópicos como el presente caso, bilaterales, con frecuentes calcificaciones y rara vez de evolución agresiva mientras que los que no se asocian a este síndrome tienden a ser únicos, grandes, unilaterales y pueden presentar invasión y metástasis. ${ }^{3}$ 
Garza-Elizondo R, et al. Tumor ovárico de cordón sexual y síndrome de Peutz-Jeghers

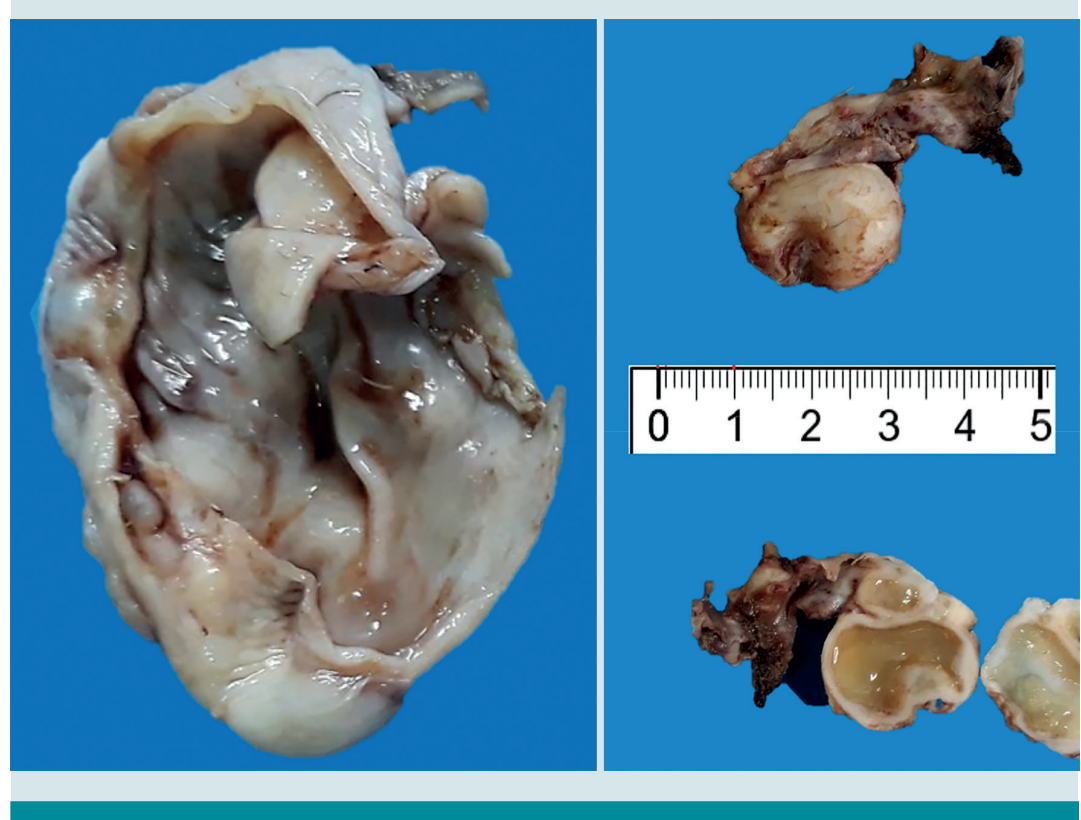

Figura 6. Pieza quirúrgica, anexo izquierdo. Cistadenoma mucinoso con quiste ovárico mayor (izquierda) y quistes menores con trompa uterina (derecha).

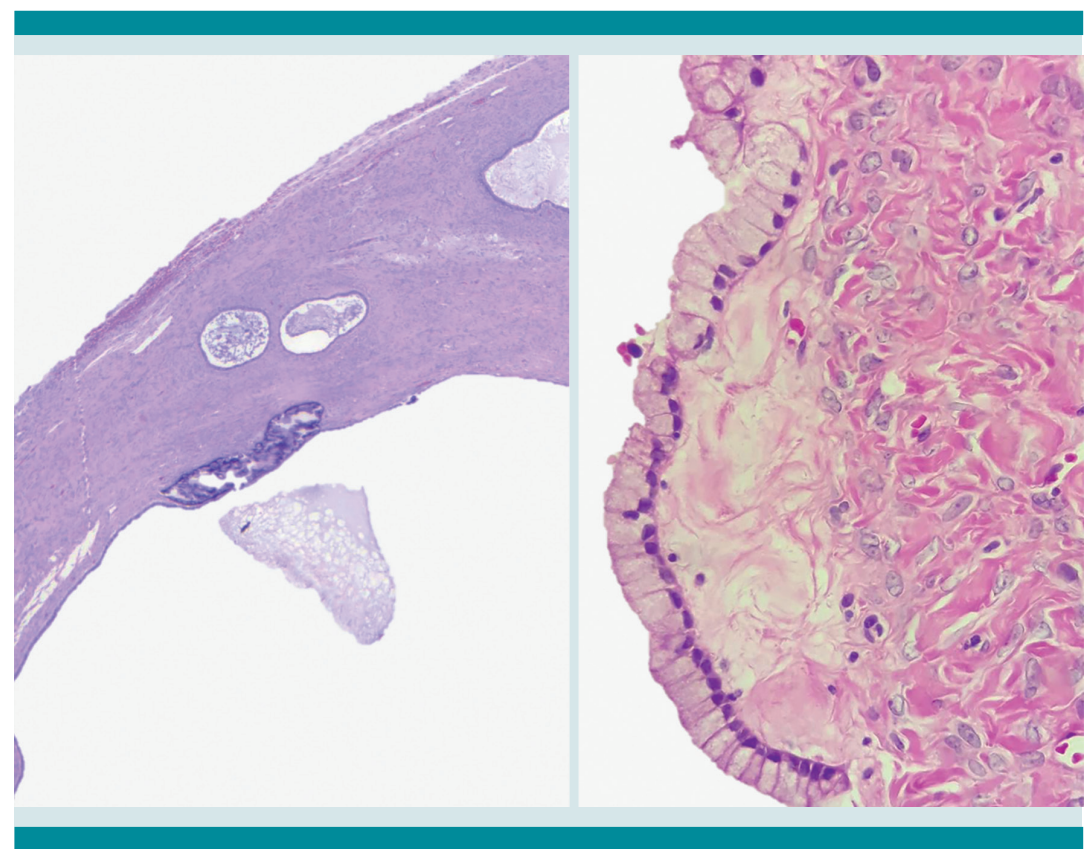

Figura 7. Cistadenoma mucinoso en el ovario izquierdo, con calcificaciones en la pared (izquierda) y revestimiento de epitelio mucoproductor con núcleos basales sin estratificación ni atipia (derecha). 


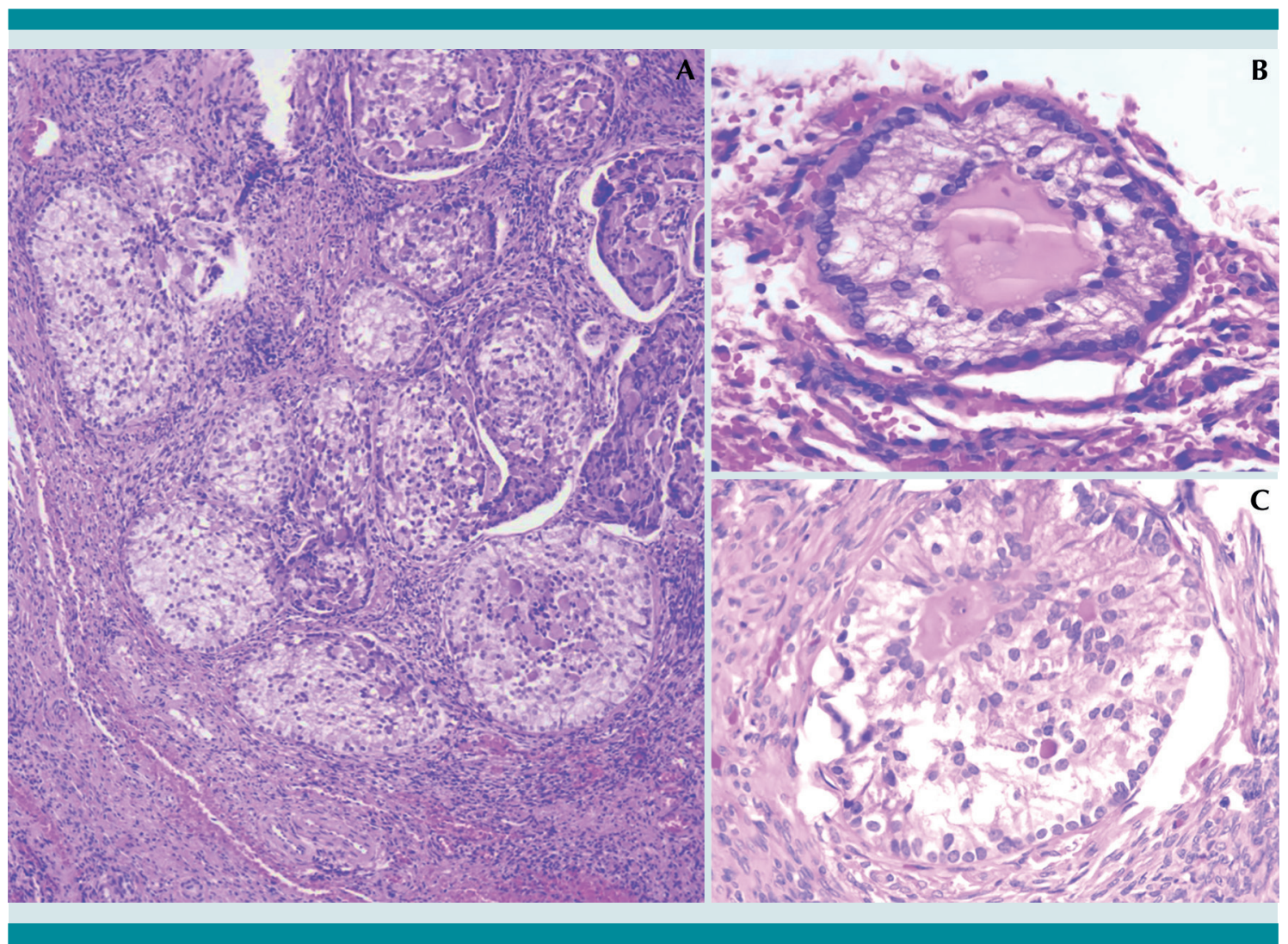

Figura 8. Ovario izquierdo. A) Tumor de cordón sexual con túbulos anulares; B) simples y C) compuestos.

Si bien se acepta que el síndrome de PeutzJeghers se asocia con mutaciones en el gen STK11/LKB1 (originalmente Ilamado LKB1 por liver kinase y al precisarse la naturaleza de la cinasa hepática referida, la designación actual es STK11, por serine threonine kinase. Ambas designaciones aparecen, juntas o por separado, en la bibliografía reciente), ubicado en el cromosoma 19, es cierto que sucede en 2 de cada 3 casos de síndrome de Peutz-Jeghers y permanece una tercera parte sin identificarse la alteración de este gen. Esto resalta particularmente porque los casos con tumor de Scully asociados con Peutz Jeghers suelen no tener mutaciones en STK11/ LK31.4,5 Esto parece conducir a una situación de mayor heterogeneidad, donde quizá los genes adyacentes o próximos (v.gr. SBNO2, GPX4) modulan la actividad del gen originalmente propuesto, lo que resulta y explica la reconocida variabilidad fenotípica del síndrome.

\section{Comentario clínico y recapitulación \\ Dras. Garza Elizondo y González del Ángel}

A los 14 años de edad, la revisión posquirúrgica evidenció afección mucocutánea en el labio inferior y la cavidad oral, característicos del síndrome de Peutz-Jeghers (Figura 9), además de una masa axilar izquierda, de $6 \times 6 \mathrm{~cm}$, blanda, no dolorosa, con areola y pezón, sin telorrea (Figura 10), correspondiente a polimastia o mama supernumeraria o accesoria. 
Garza-Elizondo R, et al. Tumor ovárico de cordón sexual y síndrome de Peutz-Jeghers

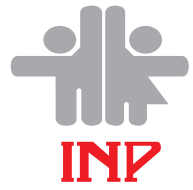

El síndrome de Peutz-Jeghers es una alteración autosómica dominante; en este caso la rama materna fue la afectada y asociada con los pólipos en el conducto gastrointestinal y la neoplasias ginecológicas v.gr. tumor de cordones sexuales con túbulos anulares en el ovario. Los tumores del cordón sexual con túbulos anulares del ovario asociados con síndrome de Peutz-Jeghers suelen aparecer en la cuarta década de la vida,

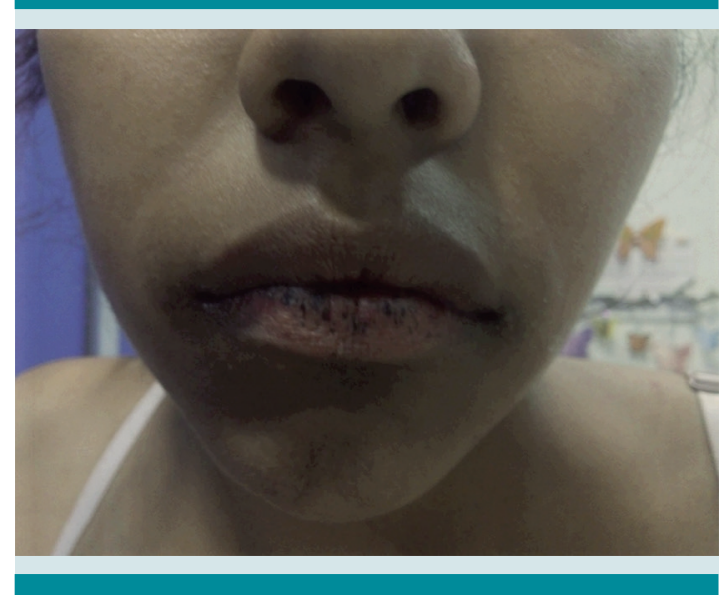

Figura 9. Pigmentación en el labio inferior. comparados con los que se expresan sin la asociación, que se manifiestan durante la tercera década de la vida.

Las mutaciones de STK11 se detectan en 70$80 \%$ de los pacientes con el síndrome de Peutz Jeghers. ${ }^{6}$ Los pacientes con mutaciones germinales de STK11 tienen mayor riesgo de padecer cáncer colorrectal, de mama, intestino delgado, páncreas, estómago y ovario (se refiere un riesgo aproximado de 35\% de cáncer a los 65 años), por lo que Kopacova y su grupo ${ }^{7}$ establecieron los criterios para el diagnóstico y tratamiento a seguir en los pacientes con esta enfermedad.

La bibliografía señala que las mutaciones en el exón 3 del gen STK11 condicionan mayor riesgo de cáncer; sin embargo, este hallazgo no se ha confirmado en otros reportes, por lo que se considera poco clara la correlación entre el genotipo y el cuadro clínico de los pacientes con síndrome de Peutz-Jeghers en quienes se identifica una variante patogénica en STK11. Tampoco se han observado diferencias en la evolución clínica de quienes no se identifican alteraciones en dicho gen.

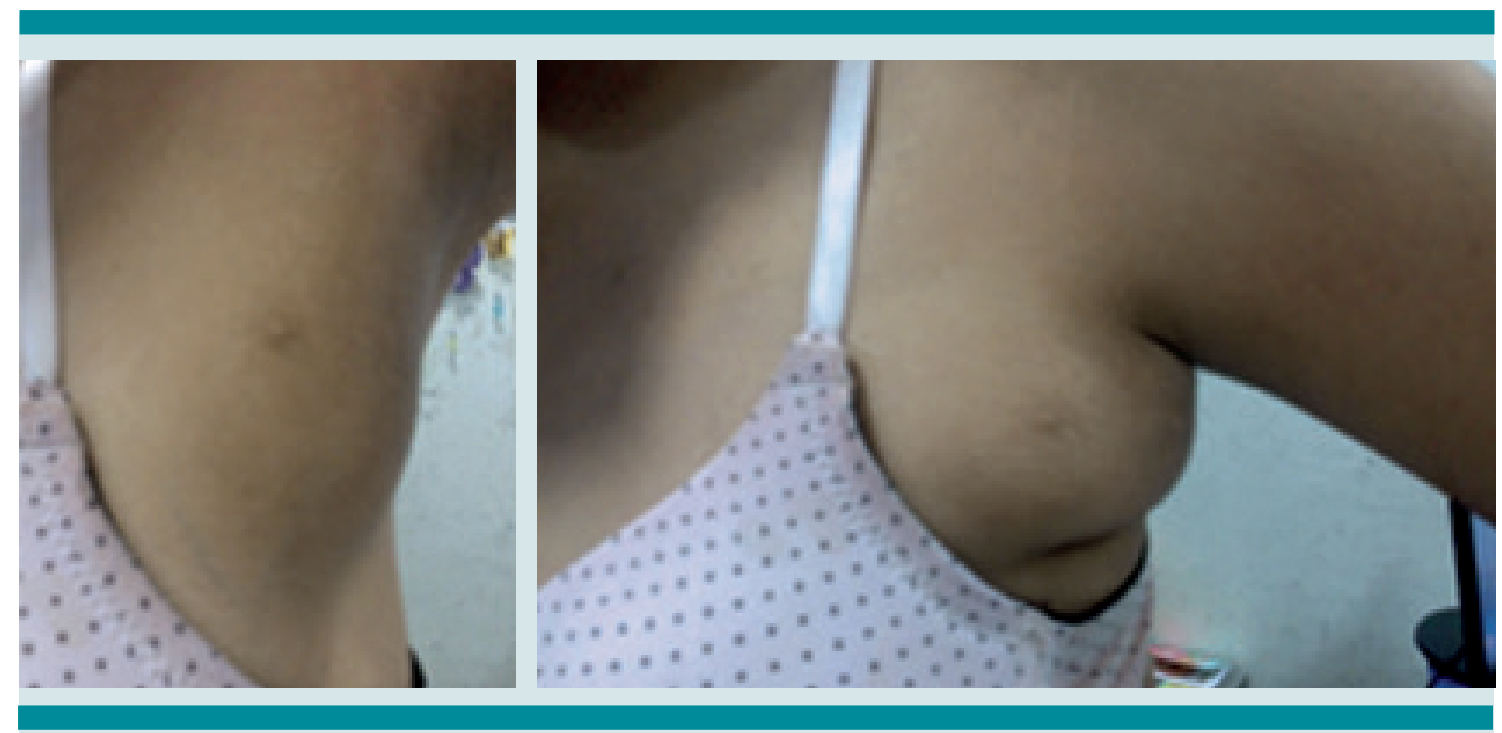

Figura 10. Mama supernumeraria. 
El síndrome de Peutz-Jeghers varía en cuanto a gravedad y manifestaciones (expresividad variable y pleiotropismo, respectivamente), incluso entre personas de la misma familia, por lo que es importante el seguimiento después del alta hospitalaria, debido a la posibilidad de transformación maligna de los pólipos y sus comorbilidades.

En el servicio de Genética se le brindó asesoría, por tratarse de una enfermedad autosómica dominante en la madre, cuando la paciente tenía 18 meses de edad; sin embargo, la familia no regresó al servicio, por lo que la paciente no ha recibido asesoría genética ni cuenta con el estudio molecular confirmatorio, que puede ser útil en caso de embarazarse y solicite el diagnóstico prenatal, para conocer si su descendencia puede heredar el padecimiento, pues el riesgo es de $50 \%$ en cada gestación.

Llama la atención la coexistencia de mama supernumeraria o accesoria, que no está descrita como manifestación clínica del síndrome de Peutz-Jeghers y es poco frecuente en la población general $(0.22-6 \%)$, incluso puede ser un sitio de neoplasias benignas o malignas, propias del tejido mamario, reportada en mujeres adultas (0.3-0.6\% de todos los casos de cáncer de mama, aunque de estos $94 \%$ se producen en el tejido aberrante y sólo 6\% en la mama accesoria). ${ }^{8,9}$ Por tanto, debe mantenerse en observación, haciendo conciencia en la autoexploración mamaria.

Hoy día la paciente permanece en seguimiento, en las consultas de Ginecología y Gastroenterología, con evolución favorable (la última a los 16 años y 9 meses; actualmente cursa el tercer semestre de bachillerato, con promedio de 8.7).

La adolescente (con enfermedad crónica) y su familia se encuentran angustiados, la madre afectada con el mismo padecimiento no recibe tratamiento ni entiende la afección importante de su hija; cuenta con familiares afectados que tampoco reciben tratamiento y permanecen sin problemas evidentes, por lo que es importante integrar al protocolo multidisciplinario la atención del servicio de Salud Mental para el tratamiento emocional de la familia, además de asesoría genética, debido a la alta incidencia de afección familiar.

\section{REFERENCIAS}

1. Banno K, et al. Hereditary gynecological tumors associated with Peutz-Jeghers syndrome (Review). Oncol Lett 2013;6(5):1184-1188. doi: 10.3892/ol.2013.1527

2. Scully RE. Sex cord tumor with annular tubules; a distinctive ovarian tumor of the Peutz-Jeghers syndrome. Cancer 1970;25(5):1107-21. DOI: 10.1002/1097-0142(197005)25:5<1107::aidcncr2820250516>3.0.co;2-7

3. Young $\mathrm{RH}$, et al. Ovarian sex cord tumor with annular tubules: review of 74 cases including 27 with Peutz Jeghers syndrome and four with adenoma malignum of the cervix. Cancer 1982;50(7):1384-1492. DOI: 10.1002/1097-0142(19821001)50:7<1384::aidcncr2820500726>3.0.co;2-5

4. Connolly DC, et al. Somatic mutations in the STK11/LKB1 gene are uncommon in rare gynecological tumor types associated with Peutz-Jegher's syndrome. Am J Pathol 2000;156(1):339-45. DOI: 10.1016/S0002-9440(10)64735-9

5. Kato N, et al. The STK11/LKB1 Peutz-Jeghers gene is not involved in the pathogenesis of sporadic sex cord-stromal tumors, although loss of heterozygosity at 19p13.3 indicates other gene alteration in these tumors. Hum Pathol 2004;35(9):1101-4. https://doi.org/10.1016/j.humpath.2004.05.011

6. Beggs AD, et al. Peutz-Jeghers syndrome: a systematic review and recommendations for management. Gut 2010;59(7):975-986. DOI: 10.1136/gut.2009.198499

7. Kopacova M, et al. Peutz Jeghers syndrome: Diagnostic and therapeutic approach. World J Gastroenterol 2009;15(43):5397-5408. DOI: 10.3748/wjg.15.5397

8. Miguel-Soca PE, et al. Factores genéticos en la carcinogénesis mamaria. Rev Finlay [Internet]. 2016;6(4): 299-316. http://www.revfinlay.sld.cu/index.php/finlay/article/ view/470

9. Uribe OA, et al. Cáncer en mama axilar: Revisión de la literatura a propósito de un caso. Child Obstet Ginecol 2017;82(4):416-423. http://dx.doi.org/10.4067/s071775262017000400416 